\title{
SOSIALISASI DAN DEMO MASAK UNTUK MENURUNKAN JUMLAH BALITA STUNTING DAN WASTING DI DESA GREBEGAN, KALITIDU
}

\section{SOCIALIZATION AND COOKING DEMO TO REDUCE THE AMOUNT OF STUNTED AND WASTED CHILDREN IN GREBEGAN KALITIDU}

\author{
Hafiza Ajeng Dianing Sukma \\ Departemen Administrasi Kebijakan Kesehatan Fakultas Kesehatan Masyarakat \\ Universitas Airlangga \\ email: hafiza.ajeng.dianing-2016@fkm.unair.ac.id
}

\begin{abstract}
First 1.000 days of human's life is a golden period which will determines the quality of human's health in the next lifetime period. Unfortunately, various health problems are found that interfere with the health condition of the baby in the first 1.000 days of human's life, one of them is stunted babies and wasted babies. Stunted and wasted babies are nutritional problems faced by various countries in the World, including Indonesia. Community service is carried out in Grebegan Kalitidu, Bojonegoro. Health conditions of children under five in Grebegan in 2019 are known to have 14 stunted and/or wasted toddlers. The purpose of community service activities is to implement the program as an effort to reduce the prevalence of stunting and wasting in Grebegan. Data related to stunted and wasted toddlers were obtained by Focus Group Discussion (FGD), in-depth interviews, and questionnaires activities. The data obtained were then used for searching the root of the problem using the fishbone method and then determined the priority of alternative solutions using the MEER method. The results of calculation using MEER method then found the highest ranking intervention program that is socialization related to parenting and toddler's eating patterns and cooking demonstrations. Intervention activities carried out are expected to increase knowledge and can be applied by the community so as to reduce the prevalence of stunted and wasted children under five in Grebegan Village.
\end{abstract}

Keywords: Children, Cooking Demo, Socialization, Stunting, Wasting

abstrak

1.000 Hari Pertama Kehidupan (1.000 HPK) merupakan periode emas yang merupakan penentu kualitas kesehatan pada masa kehidupan selanjutnya. Sayangnya dalam 1.000 HPK ditemui berbagai permasalah kesehatan yang mengganggu kondisi kesehatan bayi, salah satunya adalah permasalahan bayi bertubuh pendek dan bayi bertubuh kurus. Stunting dan wasting merupakan permasalahan gizi yang dihadapi oleh berbagai negara di Dunia, tidak terkecuali Indonesia. Pengabdian masyarakat dilaksanakan di Desa Grebegan, Kalitidu, Bojonegoro. Kondisi kesehatan balita di Desa Grebegan pada tahun 2019 diketahui terdapat 14 balita yang menderita stunting dan/atau wasting. Tujuan dari kegiatan pengabdian masyarakat adalah melaksanakan program sebagai upaya menurunkan angka prevalensi stunting dan wasting di Desa Grebegan. Data berkaitan dengan stunting dan wasting didapatkan dengan kegiatan Focus Group Discussion (FGD), indept interview, dan kuisioner. Data yang didapatkan kemudian dicari akar masalah menggunakan metode fishbone dan kemudian ditentukan prioritas alternatif solusi menggunakan metode MEER. Hasil perhitungan metode MEER ditemukan program intervensi dengan ranking tertinggi yaitu sosialisasi berkaitan dengan pola asuh dan pola makan balita dan demo masak. Kegiatan intervensi yang dilaksanakan diharapkan dapat meningkatkan pengetahuan dan dapat diterapkan oleh masyarakat sehingga dapat menekan angka prevalensi balita stunting dan wasting di Desa Grebegan.

Kata Kunci: Balita, Demo Masak, Sosialisasi, Stunting, Wasting

\section{PENDAHULUAN}

1.000 Hari Pertama Kehidupan (1.000 HPK) merupakan periode emas yang merupakan penentu kualitas kesehatan pada masa kehidupan selanjutnya. 1.000 HPK terhitung sejak saat konsepsi hingga ulang tahun kedua kehidupannya. Gerakan perbaikan gizi dimana fokus terhadap 1.000 hari pertama kehidupan di skala global adalah Scalling Up Nutrition (SUN) dan Gerakan Nasional Sadar Gizi dalam Rangka Percepatan Gizi pada 
1.000 Hari Pertama Kehidupan. Adanya gerakan perbaikan gizi tersebut disebabkan pada masa 1.000 HPK sering dihadapkan oleh berbagai masalah kesehatan. Permasalahan kesehatan dapat dalam berbagai aspek. Jika ditinjau dari aspek pemenuhan gizi, terdapat salah satunya yang marak terjadi pada $1.000 \mathrm{HPK}$, yaitu masalah gizi kronis diaman dapat berupa bayi bertubuh pendek (stunting) dan bayi bertubuh kurus (wasting) (Bappenas RI 2013).

Terdapat asumsi jika kondisi badan bayi termasuk kondisi tinggi badan kurang dan berat badan kurang disebabkan oleh kerutunan. Namun gizi buruk kronis yang ditandai diketahui bahwa kondisi stunting dan wasting penyebab terpentingnya adalah berkaitan dengan lingkungan hidup sejak konsepsi sampai anak tersebut berusia 2 tahun yang sebenarnya dapat diubah dan diperbaiki (Bappenas RI 2013). Hal ini menandakan bahwa 1.000 HPK merupakan masa yang perlu diperhatikan agar gizi balita dapat dipenuhi dan jika tidak terpenuhi dapat segera diperbaiki agar kondisi pada masa selanjutnya tidak mengalami permasalahan gizi dimana termasuk stunting dan wasting.

Stunting adalah kondisi pertumbuhan pada anak yang gagal dimana kekurangan gizi yaitu berupa zat besi (Guidelines for Food Fortification). Wasting adalah kekurangan gizi akut yang merupakan akibat dari penurunan berat badan secara drastis atau kegagalan penambahan berat badan (UNICEF Indonesia 2019). Kedua kondisi tersebut dapat meningkatkan angka kematian pada bayi ataupun balita. Stunting dan wasting adalah permasalahan global berkaitan dengan kesehatan balita. Stunting menyebabkan 1.000.000 kematian tiap tahunnya dan wasting menyebabkan sebanyak 800.000 kematian (Khara, et al. 2018). Sedangkan di Indonesia, pada tahun 2018 sebanyak 3 dari 10 anak balita menderita stunting dan 1 dari 10 anak balita menderita wasting (UNICEF Indonesia 2019). Berdasarkan data tersebut dapat diketahui bahwa kondisi stunting dan wasting merupakan permasalah gizi balita yang masih sering terjadi. Kondisi stunting dan wasting pada balita di Jawa Timur juga merupakan permasalahan yang menjadi perhatian. Menurut data Riskesdas pada tahun 2017, angka stunting di Jawa Timur masih mencapai angka diatas $30 \%$.

Kabupaten Bojonegoro merupakan salah satu kabupaten yang terletak di Jawa Timur. Kabupaten Bojonegoro tediri dari 28 kecamatan, dimana terdapat 419 desa dan 11 kelurahan (Widodo, Warsito and Wulandari 2018). Menurut penelitian Laksono \& Megatsari (2020), prevalensi balita stunting di Bojonegoro berkaitan dengan stunting tergolong kategori rendah dimana kategori rendah adalah jika angka prevalensi dibawah 14\%. Tepatnya pada tahun 2019 prevalensi balita stunting di Bojonegoro adalah sebesar 7,45\% dan prevalensi balita wasting adalah sebesar 10,2\%.

Terhitung pada bulan Juli 2019, dari 1.621 jiwa yang bertempat tinggal di Desa Grebegan, 106 jiwa diantaranya adalah balita. Rumus perhitungan gizi untuk mengetahui prevalensi yang digunakan yaitu perhitungan stunting adalah tinggi badan menurut usia $(\mathrm{TB} / \mathrm{U})$ dan wasting adalah berat badan menurut tinggi badan $(\mathrm{BB} / \mathrm{TB})$ (Izwardy 2020). Sebanyak 3 balita mengalami stunting, 1 balita mengalami wasting, dan 11 balita mengalami stunting dan wasting. Dapat disimpulkan bahwa sebesar 14,1\% balita di Desa Grebegan mengalami stunting dan atau wasting. Prevalensi ini memang berada di bawah prevalensi angka stunting dan wasting di Jawa Timur, namun berada jauh diatas prevalensi angka stunting di Bojonegoro. 
Kegiatan pengabdian masyarakat pada kali ini dilaksanakan program sosialisasi pola asuh dan pola makan balita yang sesuai dan demo masak sebagai upaya menurunkan angka balita yang mengalami stunting dan wasting di Desa Grebegan. Tujuan dari kegiatan pengabdian masyarakat yang dilaksanakan adalah sebagai salah satu bentuk upaya untuk menurunkan angka stunting dan wasting di Desa Grebegan dengan meningkatkan pengetahuan ibu berkaitan dengan pola asuh dan pola makan balita yang baik beserta pemberian informasi beserta contoh makanan yang memiliki gizi cukup untuk balita melalui kegiatan demo masak.

\section{METODE PENGABDIAN MASYARAKAT}

Kegiatan pengabdian masyarakat yang dilaksanakan merupakan hasil kerjasama antara mahasiswa, kader kesehatan Desa Grebegan, Bidan desa, perangkat desa, dan pihak Universitas Airlangga. Kegiatan yang dilaksanakan adalah:

\section{Sosialisasi}

Materi sosialisasi yang diberikan adalah berkaitan dengan pola asuh dan pola makan anak dimana kegiatan ditujukan kepada seluruh ibu PAUD Anyelir. Pengisi materi dari kegiatan adalah mahasiswa dimana didampingi oleh kader kesehatan Desa Grebegan. Analisis data yang dilakukan dalam kegiatan ini adalah berkaitan dengan tingkat pengetahuan ibu berkaitan dengan pola asuh dan pola makan anak dimana diukur menggunakan kegiatan pre test dan post test.

\section{Demo Masak}

Kegiatan selanjutnya adalah demo masak yang ditujukan kepada ibu dari anak yang menderita stunting dan/atau wasting di Desa Grebegan. Kegiatan demo masak juga disertai oleh kegiatan penyuluhan dimana materi disampaikan oleh mahasiswa dan kegiatan pelaksanaan demo masak didampingi oleh kader kesehatan Desa Grebegan. Analisis data yang dilakukan dalam kegiatan ini adalah berkaitan dengan tingkat pengetahuan ibu berkaitan dengan gizi seimbang dimana diukur menggunakan kegiatan pre test dan post test.

\section{HASIL DAN PEMBAHASAN}

Kegiatan pengabdian masyarakat dilaksanakan di Desa Grebegan. Desa Grebegan terletak di Kecamatan Kalitidu, Kabupaten Bojonegoro. Desa Grebegan dibatasi berbagai daerah dimana disebelah utara dibatasi oleh Desa Brenggolo, sebelah selatan dibatasi oleh Desa Jelu Kecamatan Ngasem, sebelah barat dibatasi oleh Desa Talok, dan sebelah timur dibatasi oleh Desa Kalitidu. Luas wilayah Desa Grebegan adalah sebesar 242.000 Ha. Jumlah seluruh warga Desa Grebegan pada tahun 2019 adalah sebanyak 1.621 jiwa yang terjadi ke dalam $512 \mathrm{KK}$.

\section{Kegiatan Pengumpulan Data}

Masalah yang dihadapi oleh Desa Grebegan berkaitan dengan kesehatan balita adalah balita gizi kurang. Berdasarkan masalah tersebut, maka perlu untuk diketahui akar masalah dimana akar masalah tersebut akan dijadikan latar belakang dari penentuan program yang akan dilaksanakan. Data berkaitan dengan penentuan akar masalah didapatkan secara primer yaitu dengan kegiatan Focus Group Discussion (FGD), indepth interview, dan kuisioner. 
Focus Group Discussion (FGD) dilaksanakan dengan kader kesehatan Desa Grebegan untuk mengetahui berkaitan dengan kondisi masyarakat terutama keluarga yang memiliki balita gizi kurang. FGD dilaksanakan sebanyak 1 kali dengan jumlah kader sebanyak 10 anggota kader beserta Bidan Desa selaku ketua kader. Berdasarkan hasil FGD dapat diketahui permasalahan terjadinya gizi kurang di Desa Grebegan didasari oleh berbagai hal, antara lain pola makan yang tidak sesuai, pola asuh keluarga yang kurang sesuai, tidak terpenuhi indikator Perilaku Hidup Bersih dan Sehat (PHBS) dan Rumah Sehat, sebagian balita tidak mengikuti posyandu secara rutin, dan frekuensi penyuluhan yang kurang.

Selain kegiatan Focus Group Discussion juga dilaksanakan kegiatan indept interview. Populasi dari kegiatan in-depth interview adalah keluarga yang memiliki balita di Desa Grebegan. Sampel yang digunakan adalah sebanyak 86 keluarga (dapat diwakilkan oleh salah satu anggota keluarga) dari total sebanyak 106 keluarga yang memiliki balita. Pertanyaan yang diajukan dalam indept interview antara lain adalah karakteristik responden, karakteristik dan antropometri balita, karakteristik keluarga, pendapatan rumah tangga, perilaku terhadap pelayanan kesehatan, pola asuh, pola makan, dan sanitasi lingkungan dan personal hygiene. Berdasarkan kegiatan in-depth interview diketahui bahwa permasalahan yang dihadapi oleh masyarakat berkaitan dengan gizi anak adalah pola asuh dan pola makan balita yang tidak sesuai sehingga gizi yang didapatkan oleh balita tidak sesuai dengan standar gizi pada umumnya.

\section{Kegiatan Penentuan Akar Masalah}

Hasil dari kegiatan FGD, in-depth interview, dan wawancara kemudian dipilah untuk menemukan akar masalah dengan menggunakan metode fishbone (tulang ikan). Indikator yang digunakan untuk pemilahan hasil kegiatan FGD adalah 5M, yaitu machine, method, man, money, dan market. Berdasarkan pemilahan tersebut, akar masalah yang menjadi dasar penentuan alternatif solusi adalah pola asuh dan pola makan balita yang kurang sesuai, indikator Perilaku Hidup Bersih dan Sehat (PHBS) dan indikator Keluarga Sehat yang belum terpenuhi, pemberian perhatian terhadap kondisi kesehatan ibu hamil oleh keluarga yang kurang, tingkat pengetahuan ibu berkaitan dengan gizi balita yang terbilang rendah, dan kebiasaan masyarakat membakar sampah.

Berdasarkan akar masalah tersebut maka terdapat sebanyak 5 alternatif solusi. Alternatif solusi yang didapatkan antara lain sosialisasi pola asuh dan pola makan balita, sosialisasi PHBS dan kesehatan lingkungan, pemberian tablet Fe pada ibu hamil dan remaja putri, demo masak, dan sosialisasi dan demonstrasi pengolahan sampah organik menjadi pupuk kompos.

\section{Kegiatan Penentuan Prioritas Alternatif Solusi}

Seluruh alternatif solusi yang ditemukan tersebut kemudian ditentukan prioritasnya menggunakan metode Methodology, Effectivity, Efficiency, and Relevancy (MEER). Metode MEER adalah salah satu metode yang dapat digunakan untuk menentukan prioritas alternatif solusi. Indikator dalam metode MEER adalah (1) Metodologi: tolak ukur berkaitan dengan kemudahan dalam penerapan teknologi tepat guna, (2) Efektivitas: Berkaitan dengan tolak ukur keberhasilan strategi yang dirancang yang ditujukan untuk mencapai tujuan, (3) Efisiensi: berkaitan dengan besaran dukungan 
yang dibutuhkan, (4) Relevansi: berkaitan dengan kesesuaian strategi yang dirancang dengan kegiatan organisasi (Nurdianna 2018).

Tabel 1. Hasil perhitungan Alternatif Solusi dengan Metode MEER

\begin{tabular}{|c|c|c|c|c|c|c|c|}
\hline \multirow[t]{2}{*}{ No. } & \multirow[t]{2}{*}{ Daftar Alternatif Solusi } & \multicolumn{4}{|c|}{ Nilai } & \multirow{2}{*}{$\begin{array}{l}\text { Jumlah } \\
\text { Nilai }\end{array}$} & \multirow[t]{2}{*}{ Ranking } \\
\hline & & $\mathrm{M}$ & $\mathrm{E}$ & $E$ & $\mathrm{R}$ & & \\
\hline 1 & $\begin{array}{l}\text { sosialisasi pola asuh dan pola } \\
\text { makan balita }\end{array}$ & 4 & 3 & 5 & 5 & 17 & $\mathrm{I}$ \\
\hline 2 & $\begin{array}{l}\text { sosialisasi PHBS dan kesehatan } \\
\text { lingkungan }\end{array}$ & 3 & 2 & 4 & 4 & 13 & IV \\
\hline 3 & $\begin{array}{l}\text { pemberian tablet Fe pada ibu } \\
\text { hamil dan remaja putri }\end{array}$ & 2 & 2 & 3 & 4 & 11 & V \\
\hline 4 & demo masak & 3 & 4 & 4 & 5 & 16 & II \\
\hline 5 & $\begin{array}{l}\text { sosialisasi dan demonstrasi } \\
\text { pengolahan sampah organik } \\
\text { menjadi pupuk kompos }\end{array}$ & 4 & 3 & 4 & 4 & 15 & III \\
\hline
\end{tabular}

Sumber: Data Primer

Hasil dari perhitungan menggunakan metode MEER, telah ditentukan ranking tertinggi hingga terendah berdasarkan jumlah nilai pada tiap indikator. Alternatif solusi yang diprioritaskan adalah dua kegiatan dengan nilai tertinggi, yaitu sosialisasi pola asuh dan pola makan balita dan demo masak.

\section{Lokasi, Waktu Pelaksanaan, dan Durasi}

Kegiatan sosialisasi dilaksanakan di PAUD Anyelir Desa Grebegan dan kegiatan demo masak dilaksanakan di Balai Desa. Kegiatan sosialisasi dilaksanakan pada 18 Juli 2019. Sedangkan kegiatan demo masak dilaksanakan pada 23 Juli 2019. Durasi dari kedua kegiatan adalah selama 2 jam.

Dikarenakan kegiatan berfokus pada bayi hingga balita (0-59 bulan), maka dari itu sasaran dari kegiatan adalah ibu yang memiliki balita. Dikarenakan seluruh balita yang bertempat tinggal di Desa Grebegan merupakan murid PAUD Anyelir, maka dari itu kegiatan dilaksanakan di PAUD dan balai desa dimana kedua tempat terletak di lokasi yang sama.

\section{Kegiatan Sosialisasi Pola Asuh dan Pola Makan balita}

Kegiatan sosialisasi berkaitan dengan pola asuh dan pola makan balita dilaksanakan sebanyak satu kali pada tanggal 18 Juli 2019. Sasaran dari kegiatan sosialsasi adalah ibu dari murid PAUD dimana di Desa Grebegan terdapat satu PAUD yaitu PAUD Anyelir. Pemilihan sasaran tersebut adalah balita di Desa Grebegan sebagian besar bersekolah di PAUD Anyelir. Pengambilan topik berkaitan dengan pola asuh dan pola makan balita sesuai dengan data Dinas Kesehatan Kabupaten Bojonegoro (2013), dimana stunting dan wasting pada balita sebagian besar $(54,17 \%)$ disebabkan oleh pola asuh ibu yang kurang baik. Maka dari hal tersebut, maka kegiatan sosialisasi bertujuan untuk meningkatkan pengetahuan ibu dari murid PAUD berkaitan dengan pola asuh dan pola makan balita yang baik agar terhindar dari stunting dan wasting.

Kegiatan sosialisasi juga ditunjang dengan pembagian media berupa leaflet berkaitan dengan materi yang disampaikan pada saat sosialisasi. Tolak ukur yang digunakan 
sebagai acuan ada atau tidaknya peningkatan pengetahuan ibu adalah menggunakan metode pre test dan post test. Kegiatan dilaksanakan selama 2 jam dimana terdiri dari kegiatan pembukaan pre test dan post test, sosialisasi, tanya jawab, dan penutup.

Jumlah dari ibu murid PAUD Anyelir adalah sebanyak 20 ibu. Kegiatan sosialisasi dihadiri oleh sebanyak 20 ibu dan seluruh ibu mengikuti kegiatan pre test dan post test. Maka dari itu pencapaian berkaitan dengan kehadiran dan jumlah yang mengerjakan pre test dan post test adalah sebesar $100 \%$. Kisaran nilai pre test dari ibu adalah 12,5-87,5. Sedangkan kisaran nilai post test dari ibu adalah 62,5 - 100. Berdasarkan hasil dari pre test dan post test terdapat peningkatan nilai dimana nilai rata-rata dari pre test adalah sebesar 62,5. Sedangkan nilai rata-rata pada post test adalah sebesar 85. Peningkatan hasil nilai pre test dan post test menandakan adanya peningkatan pengetahuan dan pemahaman ibu berkaitan dengan pola asuh dan pola makan balita yang baik.

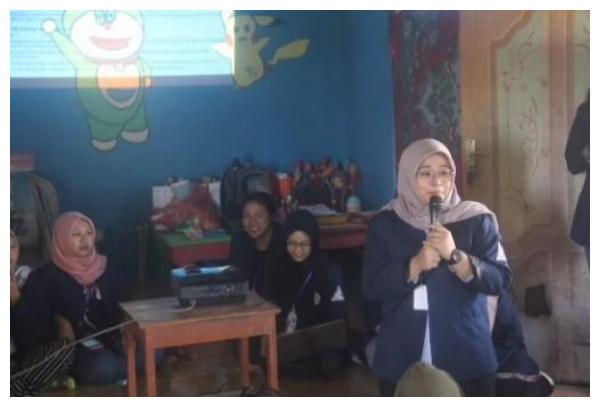

Gambar 1. Kegiatan Sosialisasi

Setelah kegiatan berlangsung kemudian dilaksanakan evaluasi dengan kriteria efektivitas, efisiensi, perataan, responsivitas, kecukupan, dan ketepatan. Efektivitas kegiatan dapat ditinjau dari ketepatan sasaran dan intervensi yang diberikan berupa edukasi dirasa sudah cukup efektif. Berkaitan dengan efisiensi ditinjau dari optimalisasi sumber daya yang cukup sesuai dimana pelaksanaan kegiatan tidak membutuhkan banyak sumber daya, dikarenakan kegiatan sosialisasi berfokus pada pemberian materi yang disampaikan secara lisan dan menggunakan alat bantu proyektor. Perataan telah sesuai dikarenakan telah mengundang seluruh ibu yang memiliki balita dari seluruh RT yang ada di Desa Grebegan. Responsivitas kegiatan dapat ditinjau dari hubungan timbal balik yang tercipta antara masyarakat dengan intervensi yang diberikan berupa komunikasi dua arah yang berlangsung dengan lancar dan antusiasme yang tinggi oleh ibu balita dalam sesi tanya jawab. Kecukupan dilihat dari teknis pelaksanaan yang telah terlaksana sesuai recana. Kriteria terakhir yaitu ketepatan dilihat dari sasaran yang sesuai dengan kegiatan materi intervensi sehingga pengetahuan yang didapatkan oleh kelompok sasaran dapat diterapkan dalam kehidupan sehari-hari.

\section{Kegiatan Demo Masak}

Kegiatan selanjutnya adalah kegiatan demo masak. Sasaran kegiatan demo masak adalah ibu yang memiliki balita yang stunting, wasting, ataupun stunting dan wasting. Tujuan dari kegiatan demo masak adalah untuk meningkatkan pengetahuan ibu berkaitan dengan pemberian makanan dengan kandungan gizi yang mencukupi untuk balita serta pelaksanaan demo masak dimana ditujukan dapat menjadi alternatif masakan yang dapat diberikan pada balita. Menu makanan yang dibuat dalam kegiatan demo masak adalah bola tahu dimana bahan yang digunakan adalah bahan yang mudah 
didapatkan di sekitar Desa Grebegan dengan harga yang terjangkau namun memiliki gizi yang cukup untuk balita. Bahan yang digunakan antara lain adalah tahu, telur, ayam cincang, wortel, kentang, bayam, daun bawang, bawang putih, bawang merah. garam, minyak, dan lada bubuk (jika tersedia). Setelah kegiatan demo masak dilaksanakan kemudian diadakan acara makan bersama khusus untuk balita undangan. Kegiatan demo masak juga ditunjang oleh media berupa leaflet yang dibagikan kepada peserta yang hadir dimana isi dari leaflet tersebut berkaitan dengan edukasi mengenai gizi seimbang beserta resep yang digunakan pada saat demo masak agar resep dapat diterapkan sendiri di rumah.

Kegiatan demo masak dihadiri oleh sebanyak 13 ibu yang memiliki balita dengan kondisi gizi kurang. Jika disesuaikan dengan data jumlah balita yang mengalami gizi kurang, sebanyak 2 ibu tidak menghadiri kegiatan. Dikarenakan kegiatan demo masak juga terdapat kegiatan sosialisasi maka dilaksanakan kegiatan pre-test dan post-test untuk mengetahui ada atau tidaknya peningkatan pengetahuan peserta berkaitan dengan gizi seimbang. Seluruh ibu yang hadir mengikuti kegiatan pre-test dan post-test. Kisaran nilai pre-test adalah 57-86. Sedangkan kisaran nilai post-test adalah 71-100. Terdapat peningkatan rata-rata hasil pre-test dan post-test dimana rata-rata pre-test adalah sebesar 72,4 dan rata-rata nilai post-test sebesar 85,7 , sehingga terdapat peningkatan rata-rata nilai sebesar 13,3 .
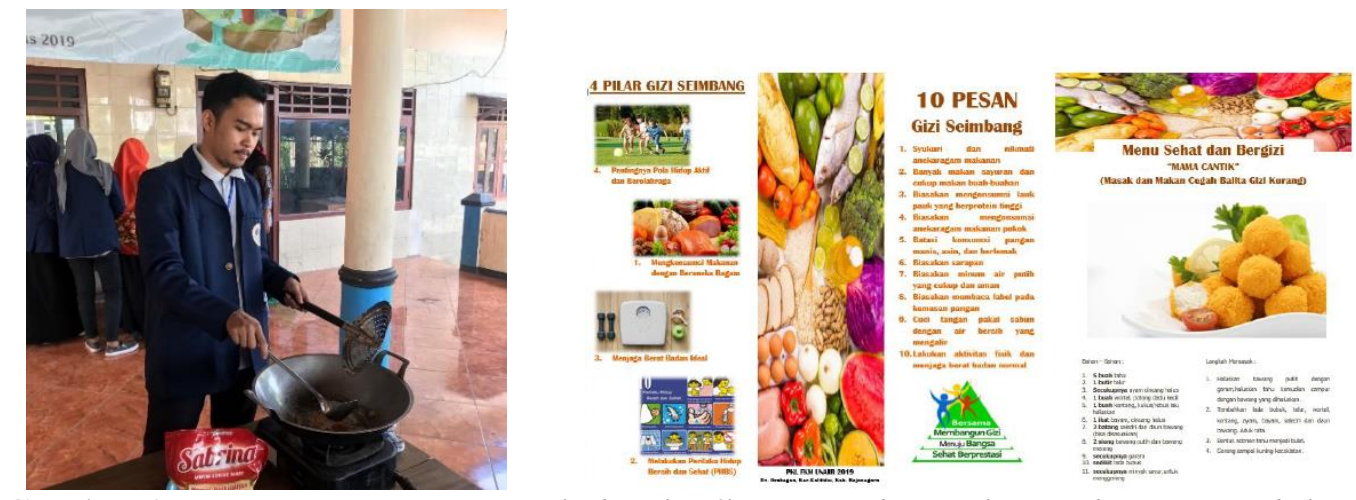

Gambar 2. Kegiatan Demo Masak dan leaflet yang digunakan Sebagai Pendukung

\section{PENUTUP \\ Simpulan}

Kegiatan pengabdian masyarakat dilaksanakan di Desa Grebegan, Kalitidu, Bojonegoro. Sasaran utama dari kegiatan pengabdian masyarakat yang dilaksanakan adalah kesehatan balita. Tujuan dari kegiatan pengabdian masyarakat adalah adalah sebagai salah satu bentuk upaya untuk menurunkan angka stunting dan wasting di Desa Grebegan. Data untuk merancang program adalah menggunakan data primer yang didapatkan dari kegiatan Focus Group Discussion (FGD), indept interview, dan kuisioner. Data tersebut kemudian diolah untuk diketahui akar permasalahan menggunakan metode fishbone atau tulang ikan. Setelah diketahui akar permasalahan kemudian ditentukan mengenai alternatif solusi dari tiap akar masalah. Alternatif solusi tersebut kemudian di ranking menggunakan metode MEER untuk menentukan alternatif solusi yang diprioritaskan. Hasil dari perhitungan metode MEER, dapat diketahui 
bahwa prioritas alternatif solusi adalah sosialisasi berkaitan dengan pola makan dan pola asuh balita dan demo masak. Materi yang terkandung dalam kegiatan yang dilaksanakan diharapkan dapat diterapkan oleh masyarakat agar dapat menekan angka stunting dan wasting di Desa Grebegan.

\section{Saran}

Saran yang diusulkan oleh tim pelaksana program pengabdian masyarakat adalah: 1) Kegiatan demo masak dapat dilaksanakan secara berkelanjutan dan rutin agar ibu dapat memiliki referensi berkaitan jenis makanan dengan jumlah gizi yang mencukupi. 2) Organisasi pemerintahan di Desa Grebegan dapat ikut berpartisipasi dalam upaya peningkatan derajat kesehatan balita di Desa Grebegan. 3) Masyarakat Desa Grebegan dapat mengingkatkan partisipasi dalam pelaksanaan program kesehatan khususnya kesehatan balita di Desa Grebegan

\section{DAFTAR PUSTAKA}

Bappenas RI. Kerangka Kebijakan Gerakan Nasional Percepatan Perbaikan dalam Rangka Seribu Hari Pertama Kehidupan (Gerakan 1000 HPK). Jakarta: Bappenas RI, 2013.

Izwardy, Doddy. Studi Status Gizi Balita Terintegrasi Susenas 2019. Jakarta: Kemenkes RI, 2020.

Kementerian Kesehatan RI. Riset Kesehatan Dasar. Jakarta: Kementerian Kesehatan RI, 2018.

Khara, Tanya, Martha Mwangome, Moses Ngari, and Carmel Dolan. "Children concurrently wasted and stunted: A meta-analysis of prevalence data of children 6-59 months from 84 countries." Wiley Maternal \& Child Nutrition, 2018: 1-7.

Laksono, Agung Dwi, and Hario Megatsari. "Determinan Balita Stunting di Jawa Timur: Analisis Data Pemantauan Status Gizi 2017." Amerta Nutrition 4, no. $2(2020)$.

Ni'mah, Cholifatun, and Lailatul Muniroh. "Hubungan Tingkat Pendidikan, Tingkat Pengetahuan dan Pola Asuh Ibu dengan Wasting dan Stunting pada Balita Keluarga Miskin." Media Gizi Indonesia 10, no. 1 (2015): 84-99.

Nurdianna, Fitri. "Implementasi Program Pengelolaan Sampah Guna Meningkatkan Kesehatan Masyarakat." Jurnal Kesehaan Pena Medika 8, no. 2 (2018).

UNICEF Indonesia. Status Anak Dunia. 2019. www.unicef.org/indonesia/id/statusanak-dunia-2019 (accessed Juli 15, 2020).

WHO. Guidelines for Food Fortification. Switzerland: WHO, 2006.

Widodo, Oky Setyo, Sunaryo Hadi Warsito, and Shelly Wulandari. "Peningkatan Kesehatan Masyarakat Melalui Pengetahuan Penyakit Zoonosis di Kecamatan Kepohbaru Kabupaten Bojonegoro." Jurnal Layanan Masyarakat Universitas Airlangga, 2018: 56-59. 